\title{
Correlation between the Alvarado Scale and the macroscopic aspect of the appendix in patients with appendicitis
}

\section{Correlação entre a Escala de Alvarado e o aspecto macroscópico do apêndice em pacientes com apendicite}

Célio Fernando de Sousa-Rodrigues ${ }^{1}$; Amauri Clemente da Rocha, TCBC-Al2; Amanda Karine Barros Rodrigues3; Fabiano Timbó Barbosa3; Fernando Wagner da Silva Ramos 3 ; Sérgio Henrique Chagas Valōes ${ }^{4}$

\section{A}

\begin{abstract}
Objective: To evaluate the possible association between the scale of Alvarado (AS) and macroscopic appearance (MA) of the appendix in patients with acute appendicitis. Methods: after receiving the diagnosis of acute appendicitis, AS data were collected. During appendectomy, MA data were collected. Data from patients without appendicitis were excluded. The Spearman correlation test was used to compare AS with Appendix MA $(p<0.05)$. Other variables were represented by simple frequency. The confidence interval $(\mathrm{Cl})$ of $95 \%$ was calculated for the correlation test. Results: Data were collected from 67 consecutive patients. The mean age was $37.1 \pm 12.5$ years and $77.6 \%$ of patients were male. The Spearman correlation test used for AS and MA was $+0.77(95 \% \mathrm{Cl} 0.65-0.85, \mathrm{p}<0.0001)$. Conclusion: although correlation was not perfect, our data indicate that a high score on the scale of Alvarado in patients with appendicitis is correlated with advanced stages of the inflammatory process of acute appendicitis.
\end{abstract}

Key words: Appendicitis. Diagnosis. Emergency medicine. Appendectomy.

\section{INTRODUCTION}

A bdominal pain is the most common situation in the emergency department ${ }^{1}$. Making the diagnosis of acute appendicitis in patients with pain in the right lower quadrant of the abdomen can be difficult, since the typical symptoms and laboratory findings may be absent in 20$33 \%$ patients with this disease ${ }^{1,2}$. The risk of acute appendicitis is higher among men than women, $8.6 \%$ and $6.7 \%$, respectively ${ }^{3}$.

The diagnosis of acute appendicitis is based on clinical history and physical examination, and imaging techniques have limited value ${ }^{4}$. The acceptable negative appendectomy rate can be $30 \%{ }^{5}$. The delay in treatment of positive patients may lead to perforation and peritonitis 6 . It is relevant to incorporate more diagnostic tools into clinical practice to benefit patients with acute appendicitis.

Tests with scores for the diagnosis have been created to assist clinicians to perform accurate diagnosis of acute appendicitis, amongst them the Alvarado score (AS) 7, the Lintula et al. Score ${ }^{8}$ and the Ohmann score ${ }^{1,6}$. Their use can reduce the rates of negative appendectomy ${ }^{1,4,6}$. The scores have values for each parameter, and the sum of the values results in various degrees of diagnostic probability for acute appendicitis 1,9 .

The most widely used score is the Alvarado one 7, which is based on three symptoms, three signals and two laboratory data. According to this score the probability of appendicitis is high when the patient receives seven or more points and appendectomy may then be indicated ${ }^{7}$.

The macroscopic appearance (MA) of the appendix was studied and classified according to the inflammatory process and the presence or absence of perforation ${ }^{10}$. This classification can stratify patients according to the degree of severity of the disease, and be used when performing the surgical procedure ${ }^{10}$. The MA may help identify patients with high likelihood of complications during hospital stay ${ }^{10}$.

The aim of this study was to evaluate the possible association between the AS and the appendix MA in patients with acute appendicitis.

\section{METHODS}

The protocol of this study was approved by the Ethics Committee of the Federal University of Alagoas

1. Department of Anatomy, University of Health Sciences of Alagoas (UNCISAL), Maceió, Alagoas - AL, Brazil; 2. Professor Osvaldo Brandao Vilela State General Hospital, Maceió, Alagoas - AL, Brazil; 3. Federal University of Alagoas (UFAL), Maceió, Alagoas - AL, Brazil; 4. Faculty of Medicine, Federal University of Alagoas (UFAL), Maceió, Alagoas - AL, Brazil. 
(protocol number 007375 / 2009-98). The consent form was presented to the participants or their legal representatives by one of the researchers prior to data collection. The participants or their legal representatives were informed of the confidentiality and security of information. This research is in accordance with Resolution 196/96 of the Brazilian National Health Council.

It is a cross-sectional study in a public hospital emergency in the city of Maceió. Data were collected between June 2009 and June 2010. Patients were invited to participate in the study after receiving a clinical diagnosis of appendicitis. Histopathologic analysis of the surgical specimen was performed to confirm the diagnosis. Data from patients without confirmation of the diagnosis of appendicitis were excluded from this research.

The inclusion criteria were: patients with clinical diagnosis of acute appendicitis. Exclusion criteria were the presence of other infections, age greater than 60 years or less than five years, hematopoietic disorders, history of immunodeficiency, and patients receiving immunotherapy.

The primary variables were: AS and Appendix MA. The secondary variables were: frequency of items from AS, the frequency of MA classes, time between diagnosis and the start of the operation and the place of origin of the patient. Additional data were: age, gender, anesthetic technique employed and surgical procedure.

The data for the Alvarado score (Table 1) were collected after the clinical diagnosis of acute appendicitis. Data for secondary variables and the additional data were collected from participants, legal guardians if the patient was under 18, and patient charts. The appendix MA was analyzed and classified during appendectomy in four groups: I, appendix without perforation and minimal changes; II, appendix without perforation and the presence of necrosis or gangrene, suppuration or necrosis; III, appendix with perforation and peritonitis or abscess at the site; and IV, appendix with perforation and diffuse peritonitis ${ }^{10}$.
The calculation of sample size resulted in the need of 67 participants, taking into consideration: the correlation between AS and MA of 0.3, significance level of $5 \%$ and a statistical power of $80 \%$. A virtual calculator was used and can be accessed at the website: http:// www.statstodo.com/StatsToDolndex.php.

Descriptive statistics were used for the variables. The confidence interval (CI) of 95\% was calculated for the primary outcome. The Spearman correlation test was used for AS and MA. We considered a significance level of $5 \%$, statistical power of $80 \%$ and two-tailed test.

\section{RESULTS}

We selected 70 consecutive patients to participate in the research. The histopathological analysis of data from three patients were not in the records, and were excluded from the study. Among the 67 participants, 77.6\% (52/67) were men. The mean age of participants was $37.1 \pm 12.5$ years.

The analysis of the AS data from the 67 participants showed that: $7.5 \%$ (5) had four points, $10.4 \%$ (7) had five points, $19.4 \%$ (13) six points, $26.8 \%$ (18) seven points, $23.9 \%$ (16) had eight points, 9.0\% (6) nine points and $3.0 \%$ (2) ten. Considering the data of MA: $7.5 \%$ (5) of patients were classified as group I; $29.8 \%$ (20) as group II; $47.8 \%$ (32) as group III; and 14.9\% (10/67) as group IV. The correlation test between AS and MA was +0.77 (95\% $\mathrm{Cl} 0.65-0.86, \mathrm{p}<0.0001)$.

Considering each item of the AS, the participants showed: migratory right iliac fossa pain in $37.3 \%$ (25) of cases; anorexia in 85.1\% (57); nausea and vomiting in $80.6 \%$ (54); abdominal wall defense in the lower right quadrant in $91 \%$ (61); rebound tenderness in $62.7 \%(42)$; temperature rise in $85.1 \%$ (57); leukocytosis in $83.6 \%$ (56); and neutrophilia (left shift) in $50.7 \%(34)$.

Table 1 - Parameters of the score of Alvarado 7.

\section{Score}

\begin{tabular}{lr}
\hline Symptom & 1 \\
Migratory Pain of right iliac fossa & 1 \\
Anorexia & 1 \\
Nausea and/or vomiting & 2 \\
Signs & 1 \\
Abdominal wall defense in the right lower quadrant & 1 \\
Rebound tenderness & 2 \\
Temperature elevation & 1 \\
Laboratory Findings & 1 \\
Leukocytosis & 10 \\
Neutrophilia (left shift) & \\
Total &
\end{tabular}


Among the 67 participants, $65.7 \%$ (44) received spinal anesthesia and $34.3 \%$ (23) received general anesthesia; $56.7 \%$ (38) were submitted to a McBurney incision and $43.3 \%$ (29) to a median incision; $31.3 \%$ (21) received simple ligation of the appendix with invagination of the stump with tobacco pouch technique, and in $68.7 \%$ (46) the stump remained free in the cavity; $44.8 \%$ (30) of patients were from Maceió, the state capital of Alagoas, and $55.2 \%$ (37) were the other cities of this state. The average time between onset of symptoms and diagnosis was $22.2 \pm 2.3$ hours. The average time between diagnosis and surgery was $10.2 \pm 3.1$ hours.

\section{DISCUSSION}

Acute appendicitis is the most common abdominal surgical condition, with a prevalence of $1: 7$, comprising $10 \%$ of the indications for abdominal operations in the emergency department ${ }^{4,11}$. The most acceptable theory for its etiology is the appendicular obstruction by foreign body, fecalith or lymphatic hyperplasia ${ }^{12}$.

Morbidity and mortality are high when in the presence of perforation and early diagnosis can reduce these rates ${ }^{13}$. The data of history and physical examination are used to make the diagnosis, but several possibilities of differential diagnosis can slow and hinder the process ${ }^{4}$. The surgeon has the responsibility of deciding the best way of managing each case $^{4}$. The three therapeutic possibilities are: hospital discharge, admission for observation and surgical treatment ${ }^{7}$. If the diagnosis is performed in negative cases or if a positive case is diagnosed late, the rate of mortality and morbidity is high 1,13 . This condition may increase the duration of use of a hospital bed, medical costs and reduced productivity ${ }^{1}$.

The symptoms of appendicitis are similar to other medical conditions, whose overlap can make the diagnosis more difficult, especially in the early stages ${ }^{14}$. The confirmation is made by surgical findings and pathological examination of the surgical specimen ${ }^{4}$. In the past, surgeons were guided by clinical findings and indicated surgical procedures earlier, leading to a rate of negative operations of $15 \%{ }^{13}$. The nontherapeutic laparotomy increase costs, as demonstrated in the United States of America, where 740 million dollars are spent a year ${ }^{15}$.

More benefits than risks are necessary in carrying out the diagnosis of acute appendicitis ${ }^{16}$. In this context, many researchers have tried to create less invasive and diagnostic methods based on the patient's history, physical examination and in less invasive diagnosis tests, such as laboratorial ones ${ }^{17}$. Given this purpose, one of the most used scores is the AS, which assigns points to parameters and adds a score presented by patients to return the diagnosis of acute appendicitis ${ }^{7}$.

AS reveals a certain probability of appendicitis in patients with abdominal pain for clinical recommendations; the sum of the scores of the items can predict the possibility of the diagnosis. The total score between 1 and 4 shows a probability of $30 \%$, between 5 and $6,66 \%$, and between 7 and $10,93 \%^{7}$. The recommendation for therapy is also based on this score: 1-4 is for hospital discharge; 5-6, observation, and 7-10, laparotomy7. Although this recommendation exists and this score has been validated in Brazil, its performance remains unknown ${ }^{16,18}$.

Leonardi et al. made a classification of patients with acute appendicitis based on appendix MA that can be used during appendectomy and observed that the inflammatory process in patients with most severe stage, group IV, had more complications and longer hospital stay ${ }^{10}$.

The hypothesis tested in this research that there is a correlation between the AS and appendix MA was confirmed, being 0.7. In clinical practice, we understand that a high score of AS is related to a more advanced stage of inflammation that can lead to more complications and longer hospital stay. The interpretation may also be that a high score of AS may be related to perforation of the appendix.

The AS was first published with a cutoff of 7 for performing appendectomy ${ }^{7}$. A systematic review analyzed 42 studies and concluded that the best cutoff point would be 5 , based on differences in sensitivity ${ }^{18}$. The sensitivity of the score 7 was $57 \%$ for men, $73 \%$ for women and $76 \%$ for children, while for a score of 5 it was $96 \%$ for men, $99 \%$ women and $99 \%$ for children ${ }^{18}$. In our study, $92.5 \%$ patients with appendicitis should be operated considering a cutoff of 5 , and $62.7 \%$ if the cutoff was 7 .

Our study showed that $44.8 \%$ of patients were from the state capital, unlike another study in Brazil ${ }^{16}$. The hospital where the study was conducted is a reference for the evaluation of cases of abdominal pain, there being no other qualified hospitals to perform this type of diagnosis or the surgical procedure in the state. This fact may explain our results. The delay in implementing the operation should be considered by health managers to implement behaviors that optimize the treatment of these patients.

The average hours of waiting for appendectomy was 10.2. In this study, 64 of 67 patients were not initially evaluated by surgeons. This fact may explain the average waiting time for execution of appendectomy at the hospital where the data were collected.

The implication for clinical practice, considering the results of this research, was to identify the presence of correlation between AS and appendix MA in patients with appendicitis. The AS can be used as a diagnostic tool for patients with abdominal pain and patients with appendicitis. We suggest the implementation of laparotomy with a cutoff of 5 , considering the sensitivity of another study ${ }^{18}$ and our own results.

The radiological imaging methods were not used for the diagnosis of acute appendicitis. One study ${ }^{19}$ 
examined the use of computed tomography in an emergency department for the diagnosis of acute appendicitis. The sensitivity, specificity, positive predictive value and negative predictive value were, respectively, $96 \%$, $75 \%, 98.5 \%$ and $50 \%$, and the overall efficiency of this radiological exam was $95 \%$. The approach we used to assess the association between AS and appendix MA in patients with acute appendicitis was observational, through a cross-sectional study, not allowing the authors to interfe- re with the diagnostic procedure used by surgeons at the hospital where the data were collected. Importantly, the imaging may reduce the instances of false negatives and allow the planning of the best surgical strategy for each particular case.

Although the correlation is not perfect, our data indicate that a high score on the scale of Alvarado is correlated with advanced stages of the inflammatory process of acute appendicitis.

\section{R E S U M O}

Objetivo: avaliar a possível associação entre a escala de Alvarado (EA) e o aspecto macroscópico (AM) do apêndice em pacientes com apendicite aguda. Métodos: depois de receberem o diagnóstico de apendicite aguda, os dados da EA foram coletados. Durante a apendicectomia, os dados do AM foram coletados. Dados de pacientes sem apendicite foram excluídos. $O$ teste de correlação de Spearman foi utilizado para comparar EA e o $A M$ do apêndice $(P<0,05)$. Outras variáveis foram representadas por frequência simples. O intervalo de confiança (IC) de 95\% foi calculado para o teste de correlação. Resultados: os dados foram coletados de 67 pacientes consecutivos. A média da idade foi 37,1 $\pm 12,5$ anos e 77,6\% dos pacientes foram masculinos. $O$ teste de correlação de Spearman usado para EA e AM foi + 0,77 (IC 95\% 0,65 a 0,85, P<0,0001). Conclusão: apesar de a correlação não ser perfeita, nossos dados indicam que uma pontuação elevada da escala de Alvarado em pacientes com apendicite está correlacionada com estágios avançados do processo inflamatório da apendicite aguda.

\section{Descritores: Apendicite. Diagnóstico. Medicina de emergência. Apendicectomia.}

\section{REFERENCES}

1. Kirkil C, Karabulut K, Aygen E, Ilhan YS, Yur M, Binneto $\square$ lu K, et al. Appendicitis scores may be useful in reducing the costs of treatment for right lower quadrant pain. Ulus Travma Acil Cerrahi Derg. 2013;19(1):13-9.

2. Velanovich $V$, Satava R. Balancing the normal appendectomy rate with the perforated appendicitis rate: implications for quality assurance. Am Surg. 1992;58(4):264-9.

3. Addiss DG, Shaffer N, Fowler BS, Tauxe RV. The epidemiology of appendicitis and appendectomy in the United States. Am J Epidemiol. 1990;132(5):910-25.

4. Khan I, ur Rehman A. Application of alvarado scoring system in diagnosis of acute appendicitis. J Ayub Med Coll Abbottabad. 2005:17(3):41-4

5. Kalan M, Talbot D, Cunliffe WJ, Rich AJ. Evaluation of the modified Alvarado score in the diagnosis of acute appendicitis: a prospective study. Ann R Coll Surg Engl. 1994;76(6):418-9.

6. Ohmann C, Yang Q, Franke C. Diagnostic scores for acute appendicitis. Abdominal Pain Study Group. Eur J Surg. 1995;161(4):273-81

7. Alvarado A. A practical score for early diagnosis of acute appendicitis. Ann Emerg Med. 1986;15(5):557-64.

8. Lintula H, Kokki H, Kettunen R, Eskelinen M. Appendicitis score for children with suspected appendicitis. A randomized clinical trial. Langenbecks Arch Surg. 2009;394(6):999-1004.

9. Impellizzeri P, Centonze A, Antonuccio P, Turiaco N, Cifalà S, Basile $M$, et al. Utility of a scoring system in the diagnosis of acute appendicitis in pediatric age. A retrospective study. Minerva Chir. 2002;57(3):341-6.

10. Leonardi LS, Brandalise NA, Mantovani M, de Medeiros RR, Fagundes JJ. Complicações da apendicite aguda. Rev Paul Med. 1974;83(4):159-64.

11. Pal KM, Khan A. Appendicitis: a continuing challenge. J Pak Med Assoc. 1998;48(7):189-92.
12. Fisher CA, Pinho MSL, Ferreira S, Milani CAC, van Santen $C R$, Marquardt RA. Apendicite aguda: existe relação entree o grau evolutivo, idade e o tempo de internação? Rev Col Bras Cir. 2005;32(3):136-8.

13. Douglas CD, Macpherson NE, Davidson PM, Gani JS. Randomised controlled trial of ultrasonography in diagnosis of acute appendicitis, incorporating the Alvarado score. BMJ. 2000;321(7266):919-22.

14. Bundy DG, Byerley JS, Liles EA, Perrin EM, Katznelson J, Rice HE. Does this child have appendicitis? JAMA. 2007;298(4):438-51.

15. Bejamin IS, Patel AG. Managing acute appendicitis. BMJ. 2002;325(7363):505-6.

16. Borges PSGN, Lima MC, Falbo Neto GH. Validação do escore de Alvarado no diagnóstico de apendicite aguda em crianças e adolescentes no Instituto Materno Infantil de Pernambuco, IMIP. Rev Bras Saúde Mater Infant. 2003;3(4):439-45

17. Jones PF. Suspected acute appendicitis: trends in management over 30 years. Br J Surg. 2001;88(12):1570-7.

18. Ohle R, O'Reilly F, O'Brien KK, Fahey T, Dimitrov BD. The Alvarado score for predicting acute appendicitis: a systematic review. BMC Med. 2011;9:139.

19. Aranda-Narváez JM, Montiel-Casado MC, González-Sánchez AJ Jiménez-Mazure C, Valle-Carbajo M, Sánchez-Pérez B, et al. Radiological support for diagnosis of acute appendicitis: use, effectiveness and clinical repercussions. Cir Esp. 2013;91(9):5748

Received on 15/12/2013

Accepted for publication 30/01/2014

Conflict of interest: none.

Source of funding: none.

\section{Mailing address:}

Fabiano Barbosa Timbo

E-mail: fabianotimbo@yahoo.com.br 